Inês Seabra Carvalho*

Universidade do Porto - ILCML

\title{
O leitor põe-se a escrever: Maria Velho da Costa na poesia de Manuel Gusmão
}

Resumo:

Um olhar sobre a obra poética de Manuel Gusmão permite identificar com clareza que, na sua poesia, permanentemente atravessada pelas vozes de outros, Maria Velho da Costa é convocada em diversos momentos como uma das vozes da alteridade que integram a busca do poeta por uma coralidade para a sua poesia. O presente trabalho pretende identificar alguns desses gestos de alusão e citação da obra de Maria Velho da Costa na obra poética de Manuel Gusmão, analisando a forma como a obra da autora ali é acolhida e transformada, revelando, entre outras, a bi-direccionalidade da relação leitura-escrita. Equaciona-se a relação entre intertextualidade e processo hermenêutico/crítico, tal como é sugerida pela continuidade observável entre os trabalhos ensaísticos de Manuel Gusmão e as suas escolhas produzidas no campo da (re)elaboração poética.

Palavras-chave:

Manuel Gusmão, Maria Velho da Costa, Dialogismo, Alteridade

Abstract:

In his search for a poetics of corality, Manuel Gusmão's poetic work is permanently crossed by the voices of others. Maria Velho da Costa is frequently summoned as one of these voices of otherness. The present work intends to identify some of those allusion and quotation gestures in the poetic's work of Manuel Gusmão, analyzing how Maria Velho da Costa's work is received and transformed in his writings and how it reveals, among others, the bi-directionality of reading-writing relationship. Suggested by the observable continuity between Manuel Gusmão's essay works and his choices produced in the field of poetic (re)elaboration, the relationship between intertextuality and the hermeneutic/critical process is considered.

Keywords:

Manuel Gusmão, Maria Velho da Costa, Dialogism, Otherness 
Pareces o Outro - diz G., a rir no duro génio, do infortúnio.

- Eu sou um Outro. Como tu.

Maria Velho da Costa

Na sua prática de teórico e ensaísta, Manuel Gusmão tem sido um dos grandes leitores de Maria Velho da Costa, tal como testemunham os textos prefaciais e posfaciais que acompanham edições das obras Casas Pardas, Missa in Albis ou O Amante do Crato, assim como as análises reunidas no volume de ensaios Uma Razão Dialógica (2011), entre os quais Manuel Gusmão se debruça sobre os livros Dores, Irene ou o Contrato Social e Myra.

Ao mesmo tempo, na sua poesia, Manuel Gusmão permite-nos identificar, com nitidez, que a voz de Maria Velho da Costa é frequentemente convocada entre as vozes que compõem a coralidade característica da sua enunciação poética.

O presente trabalho tem como ponto de partida a observação de alguns desses gestos de alusão e citação, procurando dar a ver a forma como elementos da obra de Maria Velho da Costa têm acolhimento e são transformados na obra do poeta, que sentidos adquirem e que relações estabelecem com a prática do leitor crítico Manuel Gusmão.

Os exemplos que servirão de base a este percurso encontram-se no libreto da ópera Os Dias Levantados (2002), no conto "Fátima", de A Terceira Mão (2008) e no poema "Myra ou a Ressaca da Manhã", do livro O Clamor dos Espelhos (2015).

\section{Na voz do Coro}

Os Dias Levantados - libreto da autoria de Manuel Gusmão para a ópera homónima de António Pinho Vargas, apresentada no Teatro de São Carlos, em Abril de 1998 - é uma obra que celebra, recorda e reinventa os acontecimentos da Revolução Portuguesa de Abril de 1974. Ali irrompem vozes distribuídas pelos coros e pelas personagens: os dois anjos, os quatro soldados, as três irmãs e os torcionários. Dessa multiplicidade fazem parte vozes do quotidiano, testemunhos ouvidos e apropriados, bem como palavras de outros, citadas em português e em outras línguas, cuja autoria é explicitamente grafada a bold e em parênteses, fazendo surgir, entre muitos outros, Walter Benjamin, Manuel da Fonseca, Fernando Pessoa, Gastão Cruz, William Blake, Luís de Camões, Fernão Lopes, Sá de Miranda, Rimbaud.

Entre os autores citados, encontra-se na cena 3 do Acto II - "Os dias levantados: 'The Time is out of joint'" -, um diálogo tecido com montagem de excertos de "Revolução e mulheres", editado no livro Cravo, de Maria Velho da Costa, em Abril de 1976. Agora transformadas em verso, as palavras de Maria Velho da Costa inauguram a respectiva cena e emprestam-lhe parte do título - 3. "As 3 irmãs: 'elas acendem o lume"' (Gusmão 2014: 143).

Aí, a primeira fala é atribuída ao Anjo Camponês e isola, decompondo em três versos, a primeira frase da prosa original, onde se lê: "Elas são quatro milhões, o dia nasce, elas acendem 
o lume" (Costa 1976: 133). A personagem do Anjo Camponês, imaginada a partir da invenção de Carlos de Oliveira em "Descrição da guerra em Guernica", é, para além de testemunha, uma figura que Manuel Gusmão descreve como participante, quando posta em comparação com o Anjo da História de Benjamin:

E é aqui que lateja a diferença entre os dois anjos. O facto de Carlos de Oliveira a partir de elementos da pintura inventar a figura do anjo camponês e de o fazer intervir em três momentos diferentes da descrição, faz com que o anjo não seja apenas figura de uma testemunha privilegiada, porque é aquele que dá a ver, mas também porque é a figura de um participante. [...] Dito de outra maneira, ele pode testemunhar também porque participa. (Gusmão 2018:127)

No contexto da obra e, especificamente, no contexto da cena que estamos a analisar, este entendimento da figura do Anjo Camponês confere também sentido à circunstância de esta personagem ser interpretada, ao longo de toda a ópera, por uma mulher, contribuindo para mostrar e fazer evoluir a identificação entre os diversos 'eu', 'nós' e 'elas' que se irão intensificar até ao final da cena.

Depois da fala inicial do Anjo, o canto prossegue com uma fala do Coro, dando lugar a um diálogo estabelecido com as vozes do quotidiano das três irmãs:

3. As 3 irmãs: «Elas acendem o lume»

O ANJO CAMPONÊS

Elas são quatro milhões,

o dia nasce,

elas acendem o lume.

[Maria Velho da Costa]

CORO

Elas vão à parteira que lhes diz que já vai adiantado.

Elas escondem os panos sujos de sangue.

carregadas de uma grande tristeza sem razão.

[M.V.C.]

$$
\text { A } 1^{\mathrm{a}} \text { IRMÃ }
$$

Perdi um filho.

Não sei, talvez

por força de tanto trabalhar...

ou qualquer coisa.

Depois tive outros. A gente

trabalhava e tinha os filhos

e criava-os.

Não havia cá médicos.

Isso é bom nas cidades. 
Lisboa... Tive um filho

no hospital. Lá.

(Gusmão 2014: 143; sublinhado original)

O gesto da convocatória das palavras de Maria Velho da Costa acompanha, aqui, a afirmação da Mulher como sujeito da História, ocupando o espaço público com voz e com vontade, precisamente por ter sido essa uma das mais significativas conquistas que o 25 de Abril, simultaneamente, permitiu e provocou. Mas, ao mesmo tempo, "Revolução e mulheres" faz apelo a uma outra tomada de posição porque, sendo uma narração e um tributo à tomada de consciência de um corpo social que se põe em marcha pelos seus direitos é, também, a afirmação da indissociabilidade entre a invenção verbal e a reflexão estética e política da autora sobre a sua tomada de palavra. Um gesto e um posicionamento que, num outro texto do mesmo livro Cravo, Maria Velho da Costa descreve como um dever: "Um dos vícios com que estamos alguns dos intelectuais é esse - o de obrigar-se" (Costa 1976: 89). Porque a Revolução, tempo em que o "tempo saiu enfim dos eixos" (Gusmão 2014: 144), expôs e acelerou as relações entre conquistas sociais e económicas e respectivo impacto cultural, tal como nos faz notar Manuel Gusmão:

(...) a descoberta ou a redescoberta da capacidade de falar em plenário, de participar na organização de uma comissão de trabalhadores ou de moradores; ou mesmo de um sindicato; a capacidade de organizar a própria luta e a possibilidade de, de algum modo, começar a dirigir os próprios destinos, alteram valores de comportamento social, abrem o campo da consciência social, e alargam a nossa relação com o mundo que nos rodeia. Torna-se mais intensa a necessidade, o desejo e a capacidade de Cultura e acção cultural. (Gusmão 2014a: 22)

Por outro lado, a opção poética contida na citação daquele texto de Maria Velho da Costa gera ainda outros efeitos de sentido, em particular os que resultam da montagem que dele é feito no poema que agora o acolhe. Assim parecem apontar os diálogos estabelecidos entre as vozes da autora e as vozes das irmãs, onde o diálogo entre o Coro e cada uma das três põe em evidência e faz viver a relação entre individual e colectivo, sujeito e comunidade, afirmando que "a individuação não é um processo autárcico, de solidão subjectiva" (Gusmão 2013: 49). É precisamente esse processo de formação e tomada de consciência que vemos revelar-se na progressão do diálogo e da cena, onde uma primeira troca de experiências de vida entre o 'eu' e o 'tu' das primeiras irmãs dá lugar à primeira pessoa do plural na fala da terceira irmã, corroborada, em conjunto, pelas três:

\section{$[\ldots]$}

CORO

Elas disseram à mãe e à sogra

que isso era dantes.

[M.V.C.] 
A $3^{\mathrm{a}}$ IRMÃ

É. Sim. Mudou.

Havia coisas que estavam impostas.

Nós não sabíamos bem o fundo delas.

Que qualquer coisa estava mal, sim;

mas não sabíamos ao certo o que era.

Agora ainda não sabemos tudo,

Nem da missa a metade.

Mas era a exploração, sim.

Temos a liberdade de falar, não?

CORO

Elas brigaram em casa

para ir ao sindicato e à junta.

Elas levantaram o braço nas grandes assembleias.

Elas acendem o lume.

[M.V.C.]

AS TRÊS IRMÃS

Nós.

(Gusmão 2014: 145; sublinhado original)

É a intervenção da voz colectiva do Coro que faz avançar e provoca as respostas, num diálogo que conduz ao uníssono plural, sempre em construção, porque mesmo agora ainda não sabemos tudo.

Entretanto, considerando o libreto de Os Dias Levantados como um todo, verificamos que apesar de ser extenso o conjunto de autores referenciados, poucas são as circunstâncias nas quais a citação se faz, como aqui, pela voz do Coro. Isso repete-se apenas com a citação de um verso de Sá de Miranda transformado por Luiza Neto Jorge e com alguns excertos, razoavelmente longos, de Fernão Lopes e Luís de Camões.

Olhado deste ponto de vista e colocado junto de Camões e de Fernão Lopes, o texto de Maria Velho da Costa revela com intensidade a sua natureza de narrativa épica. Nessa medida, apropriada pelo povo na voz do Coro, a narrativa presente em "Revolução e mulheres" surge lado a lado com aquelas narrativas, identificando-se com a força e a capacidade que lhes atribuímos na criação de um imaginário colectivo no qual nos reconhecemos - e com o qual nos tornamos - comunidade. 


\section{0 trabalho do humano}

"Fátima", nome associado ao milagre, é, simultaneamente, o título de um conto de Maria de Fátima Velho da Costa, publicado em Dores (1994) e, também, o título de um conto posterior de Manuel Gusmão, por via do qual o poeta inscreve uma homenagem à autora, no seu livro $A$ Terceira Mão (2008).

O leitor de Maria Velho da Costa reconhecerá com facilidade no texto de Manuel Gusmão o reenvio para o conto original, do qual se repetem, para além do título, as personagens do anjo e do estropiado, a presença do cordeiro, o pedido da criança para que o anjo dance, bem como as referências ao espaço e à visão de uma aura vermelha. A intenção de Manuel Gusmão é explícita, avisando desde o início o seu leitor que a partir daí a linguagem joga um diálogo com outro texto, cujas possibilidades verbais autorizam a sua (re)elaboração, assegurando, ao mesmo tempo, a fidelidade que vem da escuta daquilo que no conto original já existia para ser lido:

\section{Fátima}

Reconto o teu conto largo e extensível: e escuto o seu poema que se põe a devorar a própria vida e a tecer a verdade no corpo a corpo das suas almas com as várias Línguas do vivo tumultuoso. Maravilha fatal da nossa idade! Idade maior, Idade de Ouro, tu irmã maior das ondas e das vozes.(Gusmão 2015: 22)

A relação entre leitura e procedimentos intertextuais, tantas vezes implícita, é aqui deixada a descoberto, facilitando o caminho do leitor de Manuel Gusmão na busca de sentido para o seu conto. Jogando com o duplo reenvio operado pelo nome Fátima, título do conto da autora e, simultaneamente, parte do seu nome civil, o primeiro parágrafo parece dirigir-se em tom epistolar à assinatura da pessoa singular e histórica, explicitando a dedicatória e apontando uma homenagem onde não falta o diálogo com Luís de Camões.

A narração inicia-se a seguir, depois de um espaçamento no texto que a destaca do primeiro segmento. Entretanto, o que há de novo nesta narrativa merece ser articulado com a leitura crítica daquele conto, que Gusmão realiza no texto "As dores do humano", publicado em Uma Razão Dialógica (2011). Repare-se o que, nesse ensaio, diz Gusmão sobre a voz de quem narra o conto de Maria Velho da Costa:

E depois da morte do anjo é ainda, póstuma, a sua voz que narra; ou será outra que estranhamente toma o lugar da sua? Ou será que já antes era essa outra voz que contava, desdobrando-se no anjo, como em uma sua figura delegada? Podemos não ter que decidir, mas a hesitação, a passagem figural está lá, para ser lida. (Gusmão 2011: 239)

Regressando a "Fátima", de Manuel Gusmão, reconheceremos a mesma hesitação, também lá, para ser lida: por um lado, na alternância entre a terceira e a primeira pessoa e entre o uso de discurso directo e indirecto, como neste diálogo entre as duas personagens: 
«Bailá lá!» dissera eu,

«E eu bailei i, criatura angélica que da dor fiz

a insuportável alegria daquela dança do mundo» (Gusmão 2015: 22)

Por outro lado, logo de seguida, juntar-se-á a voz de um narrador, aparentemente chegado depois, que confessa sobre o estremecimento da criança: "qual a causa não sabemos".

Na leitura crítica do conto de Maria Velho da Costa, por causa do que o conto diz e pela forma como se relaciona com os outros contos do livro Dores, Manuel Gusmão sublinha "que neste conto vibra no coração da amargura e do desgosto uma alegria" (Gusmão 2011: 239), sentimento que também encontramos de forma explícita no conto do poeta:

Deu-se então a bradar em altas vozes a ver se as gentes se amotinavam, a ver se alguém vinha e o ajudava a suportar aquela tão violenta e inédita mistura de dor e alegria que o anjo diante dele executara, como quem sua própria morte em glória executa. (Gusmão 2015: 23)

Essa alegria do aleijado "que se recusa rindo a ir para o paraíso" (Gusmão 2011: 240) figurando a dupla recusa da morte e da transcendência é entendida por Gusmão, no seu comentário crítico, como "uma vibrante aceitação da imanência e da finitude terrestres" (idem: 239) e encontra correspondência, no seu conto, na "criatura terrestre, mortal e ferida sem remédio, que não quisera o céu" (Gusmão 2015: 22).

Quanto ao anjo que, no conto original, morre em "obediência e dádiva à criança aleijada que lhe pede que baile" (Gusmão 2011: 239) há, no texto de Gusmão, duas indicações que parecem apontar-nos uma determinada origem desta figura mortal. Repare-se, primeiro, na fala que lhe é atribuída em resposta ao pedido da criança ("'Bailai lá!'”): "'E eu bailei i'”(Gusmão 2015:22). Em resposta à indicação de lugar contida no pedido, " $i$ " apresenta-se, imediatamente, como versão arcaica de aí. Mas depois, mais à frente, o ' $i$ ' repete-se, numa frase que descreve a alteração do espaço e anuncia a partida do anjo: "[...] e o halo de água marinha virando roxo-enegrecendo que tremeluzia rodeando o anjo suicida: $i$ / a manhã vem vindo nos braços d'aurora" (idem: 23, itálico original). Aqui, o itálico e o uso de uma barra parecem remeter-nos para a citação de versos de um poema e justificam que voltemos à resposta do Anjo ao pedido da criança. Lida em voz alta, como pede a poesia para ser lida, nessa frase posta na fala do Anjo, a letra ' $i$ ' isolada liga-se ao tempo verbal e prolonga-o até baileii, forma de dizer que nos pode transportar para os campos do sul, onde, entre cantares tradicionais polifónicos, os alentejanos se ouvem cantar assim: "Vamos lá saindo/ por esses campos fora / e a manhã vem vindo/ dos lados d'aurora". Quer isto dizer que será possível, ao menos como hipótese, relacionar este anjo de Manuel Gusmão com o outro, o camponês, de Carlos de Oliveira, figura mortal do testemunho, a quem é "permitido o exercício efectivo da compaixão" (Gusmão 2018: 125).

Essa hipótese pode ainda ajudar-nos a dar sentido ao que acontece no trabalho de transfiguração da cena final onde a criança repete o tratamento por "vossemecê" que no conto original era dirigido ao anjo e que aqui serve para convocar o trabalho humano, do jardineiro 
comum, na concretização de uma versão terrena do Paraíso:

Sentindo-se chamado em alta grita, eis que acorre o jardineiro comum daqueles lugares. 0 estropiado diz-lhe "Disto tudo - e em o dizendo, um gesto da mão esquerda fazia, que mais que o seu palheiro abrangia - poderá vossemecê fazer um jardim?" (Gusmão 2015: 23)

\section{Dá ao vivo um pensamento}

Em "MYRA OU A RESSACA DA MANHÃ", de O Clamor dos Espelhos (2015), cujo subtítulo se apresenta "Com versos e/ou frases de William Blake, Maria Velho da Costa, Herberto Helder e Rimbaud", o poeta envia-nos, desde o início, para Myra, romance de Maria Velho da Costa publicado em 2008. As alusões à narrativa surgem a partir do terceiro verso, com a referência aos dois pares do livro - Myra e o cão; Myra e Orlando, personagem que a acolhe, educa e ama:

e amava ela um cão que a amava

e amaria um príncipe

(Gusmão 2015: 123)

Acompanhando a narrativa, o poema acolherá ainda momentos decisivos do romance, como aquele em que Myra, selando um pacto de intimidade, fixa o nome do cão:

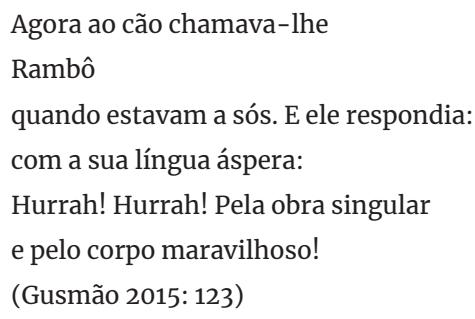

As palavras citadas e as que agora interagem com elas dão-nos a rugosidade da língua em que se inscrevem todos os nomes: "Myra agora chamava-lhe Rambô quando estavam a sós. $E$ ele respondia a todos os nomes que ela quisesse dar-lhe, porque se dava a ela" (Costa 2008: 55).

O poeta prossegue, levando-nos até à cena final do romance:

eis que termina com uma debandada de perfumes;

uma guarda de anjos de fogo e gelo

enquanto ele lhe diz: Agarra-te bem

para eu bater com a espinha antes de ti.

(Gusmão 2015: 124) 
No romance, este é o momento em que Myra decide e Rambo percebe qual vai ser o fim: "Rambo subiu, sentou-se. Percebeu que nada mais havia a perceber. Agarra-me bem, disse, para eu bater com a espinha antes de ti" (Costa 2008: 221). A citação quase integral do pedido introduziu, entretanto, uma variação mínima - a reversibilidade do pronome, que antecipa uma hesitação que nos versos finais se revelará:

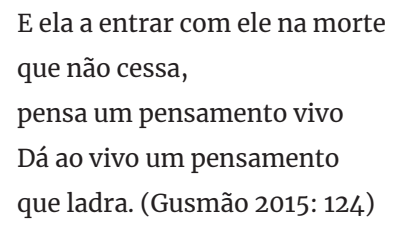

Na leitura crítica que faz do romance, em particular da cena final, Gusmão propõe nela entrever "um gesto de poética da comunicação entre o animal e o humano, no interior [...] de uma construção antropológica mais hesitante do que autoritariamente separada" (Gusmão 2011: 276). Relendo a última estrofe, encontramos parcialmente citada a frase "Foi o último pensamento vivo de Myra" (Costa 2008: 221), que fecha o romance que aqui se expande, porque no poema há ainda um outro pensamento que lhe sucede. É o que sugerem os dois versos finais, que podem ser lidos como um pensamento sobre o pensamento, sinalizando o diferimento leitura- escrita implicado na prática intertextual. E será fácil aceitar que, mesmo não sendo exposto o nexo entre leitura e interpretação, o que vemos projectar-se a partir da imagem proposta em "Dá ao vivo um pensamento/ que ladra" é precisamente a transfiguração (em) poética daquela comunicação entre o animal e o humano que, no seu trabalho crítico, Gusmão vislumbra como mais hesitante do que separada.

A experiência da leitura e a sua relação com os procedimentos intertextuais é consensualmente reconhecida. No caso de Manuel Gusmão, ela é fortemente marcada pela sua actividade de leitor crítico de poesia, sendo possível identificar, na sua obra, a presença transversal e persistente de vários autores, comuns ao campo do ensaio e ao campo da produção poética, entre os quais Maria Velho da Costa é um importante exemplo.

Num texto intitulado "Notícias da crítica", Gusmão dá conta de como "a experiência crítica pode aparecer como que a desenhar o espaço aberto para a vinda de poemas que ainda não foram escritos" (Gusmão 2011: 179), tomando parte do processo de invenção poética. Mas importa perceber que, para Gusmão, a abertura desse espaço não significa a fusão entre crítica e criação porque "[E]nquanto relação intersubjectiva que existe intertextualmente definida e socialmente condicionada, a relação crítica suporá necessariamente que um texto é outro, ou está no lugar do outro". Por isso, no mesmo texto, Gusmão defende que "o crítico tem de saber e dar a saber que não foi ele que escreveu aquilo", não havendo "outro remédio que não o prolongar a descrição e procurar explicitar ou mostrar o nexo que a articula com um princípio de interpretação" (idem: 173). O que vimos acontecer no final do poema "MYRA...", cuja leitura se fez de forma cruzada com o ensaio sobre aquele romance, foi precisamente a ocultação, nos versos, do nexo que 
articulava a descrição com a interpretação, exposta no ensaio. Nessa diferença se desenha uma fronteira de especificidade, intencionalmente mantida, entre a dimensão do trabalho ensaístico e a dimensão da invenção poética, na obra de Manuel Gusmão.

Por outro lado, se é verdade que a projecção identificativa, na qual Gusmão recusa enredar o crítico, tem mais espaço no campo da invenção poética (virá Rimbaud, ajudar a explicar o desejo de viver várias vidas), o recurso proliferante do poeta às palavras dos outros mantém sempre actual e exposto o respeito pela alteridade. Trata-se de "[V]oltar a escrever para se ver que a mão é outra" (Gusmão 2008: 30), o que deixa ao poeta uma exigência: "só podemos citar a obra de um autor quando a citamos com a nossa própria voz, isto é, quando respondemos à invenção com outra invenção" (Gusmão 2005: 12).

A defesa do conceito de invenção, que aqui explicita também uma ética, é recorrente no entendimento que Manuel Gusmão tem da poesia e torna problemática a sua relação com outras práticas, suas contemporâneas, que parecem coincidir com a do poeta no recurso a procedimentos intertextuais. Seria particularmente difícil de aceitar, por exemplo, uma leitura da obra de Gusmão à luz das características apontadas por Frederic Jameson ao pastiche, nos seus estudos sobre o ambiente cultural da pós-modernidade. A insistência de Gusmão na necessidade de "evitar a repetição sem variação" (Gusmão 2011: 178) e expor a diferença, para se ver que a mão é outra, está longe, como se percebe, da noção de "identical copy for which no original has ever existed" (Jameson 1991: 18). O poeta que, segundo Fernando Martinho, "à desolação dos tempos de crise e despedida [...], contrapõe teimosamente a força dos recomeços, a invenção, o 'nascimento das coisas"' (Martinho 2008: 67), não dá por esgotada a ressonância da palavra "novo" e, nisso, a sua poética estará mais próxima da modernidade estética do que do pós-modernismo.

Do mesmo modo, a recusa da noção romântica de originalidade não implica o afastamento da busca de uma singularidade que, para Gusmão, não seria perceptível se não tivéssemos uma linguagem comum.

A apropriação, pelo poeta, das palavras dos outros, não pode entretanto ser confundida com uma poética da posse que respondesse ao repto de Jasper Johns: "Take an object. Do something else to it" (Jonhs apud Perloff 2010: 17). Porque, como pressuposto de poética, em Manuel Gusmão o respeito pela alteridade ocupa um lugar central, indissociável de uma determinada concepção da linguagem que, a partir de Mikhail Bakhtin, irradia no seu pensamento. É de Bakhtin a advertência de que só existe relação dialógica entre sujeitos, e que o encontro de dois textos é o encontro de duas consciências, dois sujeitos: "[L]e text n'est pas un objet, en conséquence de quoi il est impossible d'en éliminer ou d'en neutraliser la seconde conscience" (Bakhtin 2017: 249).

A compreensão da forma como Gusmão integra e reelabora o legado do autor russo torna-se, como se verá, decisiva para entender o recurso permanente, na sua poética, à alusão, citação e montagem de palavras de outros. 


\title{
4. Bakhtin, Rimbaud; outros terceiros
}

\begin{abstract}
"Nenhum de nós inventa a língua em que escreve o poema" (Gusmão 2010: 14). Nesta afirmação, o que poderia ser a constatação de uma evidência dá lugar à reivindicação de uma herança, cujas implicações, como teórico da literatura e como poeta, Gusmão não se cansa de reclamar:
\end{abstract}

Only the mitical Adam, who approached a virginal and as yet verbally unqualified world with the first word, could really have escaped from star to finish this dialogic inter-orientation with the alien word that occurs in the object. Concrete historical human discourse does not have this privilege. (Bakhtin 2014: 279)

No centro do trabalho realizado por Mikhail Bakhtin em torno do conceito de Dialogismo - mas também dos conceitos que, na sua obra, emergem para o completar, como compreensão activa; Exotopia; Polifonia; Heteroglossia; Carnavalização, entre outros - está a ideia de que toda a palavra é "une sorte de pont jeté entre moi et les autres" (Bakhtin/(Volochinov) ${ }^{1}$ 2018: 123), apontando a interação verbal (o diálogo, em sentido largo) como a realidade fundamental da língua:

Toute énonciation, même sous forme écrite figée, est un réponse à quelque chose et est construite comme telle [...]. Toute inscription prolonge celles quis l'ont précédée, engage une polémique avec elles, s'attend à des réactions actives de compréhension, antecipe sur celles-ci, etc. (Bakhtin/(Volochinov) 2018: 105)

É a partir desta concepção, desenvolvida ao longo da sua obra em permanente confronto quer com a Linguística, quer com o "subjectivismo abstracto" do Romantismo, que Bakhtin procurará "transpor o abismo entre a representação abstracta do mundo, desprovida de sujeito, $e$ a vida concreta da palavra, inseparável do sujeito" socialmente organizado (Tezza 2003: 348).

Quando, a propósito das citações usadas na ópera Os Dias Levantados, Manuel Gusmão afirma: "O que para mim é decisivo é o facto de uma passagem adquirir outra significação ao ser citada" (Gusmão 2013a: 100), o que se faz presente é, ainda, a noção de acontecimento único e não reiterável, própria da concepção bakhtiniana sobre o enunciado e a linguagem:

[...] est possible la reproduction mécanique de l'empreinte du doigt (en n'importe quel nombre d'exemplaires). Il en va de même pour la reproduction, également mécanique, d'un text (la réimpression, par exemple), mais la reproduction du texte par le sujet (retour au text, relecture, exécution nouvelle, citation) est un événement nouveau, non reproductible dans la vie du texte, est un maillon nouveau dans la chaîne historique de l'échange verbal. (Bakhtin 2017: 349)

É verdade que Bakhtin, distinguindo o que designa por forças centrípetas e centrífugas na linguagem, atribuiu à poesia, em contraste com as possibilidades da multivocalidade do ro- 
mance, a tendência centralizadora e monolítica da "linguagem elevada" e dos sistemas de valores dominantes. Bakhtin não considera, no entanto, que a natureza dialógica, comum a todos os discursos, desapareça na poesia; o que entende é que ela não aparece como recurso estético, no conjunto dos procedimentos da poesia:

In genres that are poetic in the narrow sense, the natural dialogization of the word is not put to artistic use, the word is sufficient unto itself and does not presume alien utterances beyond its own boundaries. (Bakhtin 2014: 285)

É neste sentido que a busca assumida por Manuel Gusmão, de reinventar uma coralidade para a sua poesia, não só integra e reelabora os contributos de Bakhtin, como lhe responde, no sentido usado pelo próprio.

Gusmão sabe, e trabalha na sua poética, o sentido daquela "reviravolta" dialógica que a entrada das palavras dos outros no seu próprio discurso provoca, tal como é descrita por Bakhtin:

La plus légère allusion à l'énoncé d'autrui donne a la parole un tour dialogique que nul thème constitué purement par l'objet ne saurait lui donner. Le rapport au mot d'autrui, dans son principe, se distingue radicalement du rapport à l'objet. (Bakhtin 2017: 334)

Por isso, Gusmão confessa que são obsessões:

A conjugação e o conflito de registos, de modos de fala diversos. [...] A convocação das palavras dos outros, em português e noutras línguas, vindas de diferentes passados e de diferentes modos de discurso. (Gusmão 2014: 186)

O que diz, também, do desejo de "tornar-se outro" (Gusmão 2005a: 65), como refere em outro lugar, fazendo Rimbaud entrar em cena.

Num ensaio intitulado "Anonimato ou alterização?", no qual Manuel Gusmão propõe e problematiza a hipótese de uma "poética da alterização", é sugerida a seguinte reflexão, a partir do estudo de Rimbaud:

[...] a fórmula "EU é um outro", se valorizarmos a composição em versaletes de JE, ou se colocarmos o pronome entre aspas, ou ainda se simplesmente o lermos como menção de pronome e não uso dele, diz também a tensão da enunciação singular com a generalidade da língua ou da linguagem. Por outro lado, não é o desaparecimento do sujeito autoral que aqui se figura, mas antes um processo de estranhamento e alterização. Este processo, [... ] permite, sim, figurar um acontecimento da linguagem, um acontecer da escrita ou da poesia: difere a fonte da voz, mas evita o anonimato transcendental. (Gusmão 2011: 90) 
A proposta que daqui resulta e que será desenvolvida ao longo do ensaio, a partir do estudo de Fernando Pessoa e de outros autores, é decisiva na estruturação de todo o pensamento de Manuel Gusmão. Com ela se relaciona o conceito de Exotopia de Bakhtin, para quem a ideia de que em todas as formas estéticas o princípio axiológico é o outro, determina, também, a ideia da não-coincidência do sujeito da vida com o sujeito da actividade estética:

[...] lorsque nos sommes deux, ce qui importe ce n'est pas que, en plus de moi-même, il y ait encore un autre homme, semblable à moi (deux hommes), mais que, pour moi, il soit un autre [...].

La productivité de l'événement ne reside pas en ce que tous fusionnent en un mais en ce que l'exotopie soit exploitée que permet de se situer à une place qu'on est le seul à pouvoir occuper hors des autres. (Bakhtine 1984: 113)

Na obra de Manuel Gusmão, a articulação entre uma poética da alterização e uma poética da coralidade assume-se como modo de contestação e alternativa ao "anonimato do autor" que, sem abdicar da historicidade da relação literária, se posiciona, ao mesmo tempo, em linha com a modernidade que vem de Rimbaud.

E é Rimbaud quem, mutuamente convocado, ilumina ainda os encontros entre Manuel Gusmão e Maria Velho da Costa.

Com Myra, reconhecemos em Rambô esse "pequeno desvio na pronúncia que faz o seu nome soar como o de Rimbaud" (Gusmão 2011: 272). E, com o olhar sobre o poema de Gusmão, percebemos melhor que é por causa de Rimbaud que Rambô se envaidece:

Agora ao cão chamava-lhe

Rambô

quando estavam a sós. E ele respondia:

com a sua língua áspera:

Hurrah! Hurrah! Pela obra singular

e pelo corpo maravilhoso! (Gusmão 2015: 123)

Num texto de 2008 intitulado "Idade de oiro", escrito por Maria Velho da Costa para o Manuel Gusmão, encontramos no extremo de um salão "um rapaz muito jovem, pálido e loiro-pálido [...]. Está sentado a uma escrivaninha, de calções longos franzidos na orla da bainha e tem uma perna em ligaduras até ao joelho" (Costa 2008: 189). Há um conjunto de indicações que permitem ao leitor suspeitar de quem se trata mas, dentro do texto, a presença do Rapaz Raro parece atordoar G. que só durante o diálogo "reconhece aquele timbre, a voz que o trabalhou" (ibidem).

Desse diálogo encenado por Maria Velho da Costa por fora do tempo, retenhamos a última fala do Rapaz, despedindo-se de G.:

-Até logo - diz o Rapaz. - Chama-me eu de nós. Tu que vives bem a multiplicidade. Sempre tiveste 


\section{Cadernos de Literatura Comparada}

O leitor põe-se a escrever: Maria Velho da Costa na poesia de Manuel Gusmão

a cabeça aberta para cosmologias e ruínas. Um coração de oiro na língua de prata, hélas. (idem: 190)

\section{E é talvez por isso que Gusmão diz, num outro lugar:}

E, por isso, um verdadeiro outro (alter) poderá sempre vir a ser um outro terceiro. Por exemplo, MARIA VELHO DA COSTA, pode ser um outro terceiro. (Gusmão 2013b: 166, maiúsculas no original).

\section{NOTAS}

* Doutoranda em Estudos Literários, Culturais e Interartísticos e membro colaborador do Instituto de Literatura Comparada Margarida Losa.

${ }^{1}$ Mantém-se a referência da edição francesa consultada, que atribui a Bakhtin a autoria, mencionando que, na sua primeira edição (Leninegrado, 1929), a obra - onde aparece pela primeira vez a noção de dialogismo - foi publicada sob o nome de Volochinov. A relação entre as várias obras daquilo tem sido designado por "Bakhtin e o seu círculo", integrando os trabalhos publicados por Volochinov e Medvedev, não é consensual e tem sido objecto de diversos estudos, designadamente, os de Michael Holquist, tradutor de Bakhtin para a língua inglesa. Veja-se, por exemplo, o que sobre a matéria é dito em "The Architetonics of Answerability" (in Bakhtin 1990: ix-xlix, numeração romana no original) 


\section{Bibliografia}

Bakhtin, Mikhail (1990), Art and Answerability - Early Philosophical Essays by M. M. Bakhtin. Austin, University of Texas Press.

-- (2014), "Discourse in the Novel", The Dialogic Imagination. Four Essays by M. M. Bakhtin.

Austin, Texas Press University, pp. 259-422.

-- (2017), Esthétique de la création verbale. Paris, Gallimard

Bakhtin, Mikhail / Voloshinov, V. N. (2018), Le marxisme et la philosophie du langage. Essai d'application de la méthode sociologique en linguistique, Paris, Les Éditions de Minuit.

Costa, Maria Velho da (1976), Cravo, Lisboa, Moraes Editores.

-- (2008), Myra, Lisboa, Assírio\&Alvim.

-- (2008), "A idade de oiro", in Buescu, Helena Carvalhão/Basílio, Kelly Benoudis (org.), Poesia e Arte. A Arte da Poesia. Homenagem a Manuel Gusmão. Lisboa, Editorial Caminho, pp.187-190.

Gusmão, Manuel (2005), "O (re)começo da palavra", entrevista concedida a Ricardo Paulouro, in $J L, 5$ de Janeiro: $12-13$.

-- (2005a), "Sobre 'Os Dias Levantados'. Tornar-se outro - Conversa com Manuel Gusmão", Artistas Unidos- Revista, $\mathrm{n}^{0}$ 13, Março. Lisboa, Artistas Unidos/ Livros Cotovia, pp- 64-69.

-- (2008), "Temos todos um cinema metido na cabeça", entrevista concedida a Luís Miguel Queirós, in "ípsilon", Público, 27 de Junho: pp.28-30.

- - (2010), Tatuagem \& Palimpsesto da poesia em alguns poetas e poemas. Lisboa, Assírio \& Alvim.

-- (2011), Uma Razão Dialógica. Lisboa, Editorial "Avante!”.

- - (2013), "Casas Pardas - A arte da polifonia e o rigor da paixão: uma poética da individuação histórica”, prefácio a Maria Velho da Costa, Casas Pardas. Lisboa, Assírio\&Alvim, pp.8-58.

-- (2013a), "Em busca d'Os Dias Levantados", entrevista a Manuel Gusmão e António Pinho Vargas concedida a João Pedro Cachopo, Textos \& Pretextos, $\mathrm{n}^{0}{ }^{18}$. Lisboa, Centro de Estudos Comparatistas, pp. 90-103

-- (2013b), "Uma regra de poética que é também política", Contra Todas as Evidências. Poemas reunidos III. Lisboa, Editorial “Avante!”, pp. 163-166)

- - (2014), Contra Todas as Evidências. Poemas reunidos II. Lisboa, Editorial "Avante!”

- - (2014a), "A Revolução Portuguesa e o seu impacto cultural", Revista O Militante, nº331, Julho/Agosto 2014. Lisboa, Editorial "Avante!", pp.22-26.

-- (2018), Neo-realismo. Uma poética do testemunho (alguns exercícios de releitura). Lisboa, Editorial "Avante!".

Martinho, Fernando J.B. (2008), "Entre Kavafis e Camões: o recomeço da invenção. Para uma leitura de Migrações de Fogo, de Manuel Gusmão", in Buescu, Helena Carvalhão/Basílio, Kelly Benoudis (org.), Poesia e Arte. A Arte da Poesia. Homenagem a Manuel Gusmão. Lisboa, Editorial Caminho, pp.65-73.

Perloff, Marjorie (2010), Unoriginal Genius:Poetry by Other Means in the New Century. Chicago, 
The University of Chicago Press.

Tezza, Cristovão (2003), Entre a prosa e a poesia: Bakhtin e o formalismo russo. Rio de Janeiro, Editora Rocco.

Santos, Guilherme Pinto dos (2016), Ser tocado pela verdade sabendo que tudo é falso - A herança expressiva do cinema de João César Monteiro no cinema de Miguel Gomes, tese de mestrado, https://core.ac.uk/download/pdf/143388413.pdf. (último acesso 04/06/2020). 